\title{
An empirical study on the new placement systems in Universities of Arab World
}

\author{
Ginevra Gravili \\ Department of Economics, University of Salento \\ Lecce, 73100, Italy
}

\begin{abstract}
The purpose of this paper is to investigate the top Arab universities with impact in the web world, and analyzing if the support of innovative communication systems develops competitive advantage for placement in University of Arab world.

The explosion of social media communication has brought about numerous changes in every type of activity. This has altered the nature of competition, accelerating the flow of information, of new products and of services in all the world. In this context it becomes necessary for Universities to encourage graduates to enter the job market, guaranteeing their placement also with these new tools. The study includes 292 students of 16 Universities representing 20 Arab Countries.
\end{abstract}

Keywords: HRM, placement, Universities, Social networks, Arab world.

\section{Introduction}

The changes that the use of the Internet has imposed on society are profoundly changing the recruiting processes (Galanaki, 2002; Veger 2006; Verhoeven and Williams, 2008) requiring renewing and reshaping the tools to ensure a "workers profile" up to the standards of new challenges. Already in 2007 Schramm highlighted that e-recruitment was modifying itself, developing new systems that allowed businesses to reach both active and passive candidates through the use of social media. During the same period, also Gallagher and O'Leary highlighted that social media had the ability to establish a relationship of mutual interest and understanding with passive seekers, representing, thus, the key to build the foundation for a useful exchange of information. This is the era of the "any-time" and of the "any-space"; it is the time when the power of Internet has rapidly and drastically changed the communicative ways imposing more sophisticated knowledge processes.

The diffusion of new social communication has represented for Arab countries an epochal shift. At the time, it is too early to say if this shift will manage to impose also a cultural change in organizations and in their managerial choices.

In effect the history of the social media diffusion in Arab world is very particular. Used as instruments to coordinate mass protests, communicating real-time images and up-todate information, or as processes of contagion across the
Arab region, social media (as Facebook, Twitter, LinkedIn, Instagram) have managed to bypass state controlled national media, propelling images and ideas of resistance and mass defiance across the Middle East and North Africa, and they have had a capillary diffusion in restricted times and in many regions. Today, also, Universities in the Arab region are undergoing a period of rapid transition, with more than a decade of expansion in enrollment, including more female students. Since 2002, the number of institutions in the region has more than doubled, but this transition requires the adoption of strategies aimed at continuous change. In order to be "competitive", they need to evaluate and highlight new variables that allow them to respond to the global social and cultural evolution. Today, the students have got a "digital identity", they spend their free time online on the social networks, they have energy, enthusiasm and knowhow, they speak a computer language, they love virtual interaction. In this scenario, the University's main goal, apart from training, becomes that of encouraging its graduates to enter the job market, guaranteeing their placement also with the support of innovative communication tools.

Students, today, place a lot of importance on on-line job search, notification of job posting and communication through electronic means. Therefore the choice of a specific type of communication could have obvious social implications as, the more the relationship is developed in a country where there isn't a stable political situation, the more important it will be for the enterprise to speed up the message and thus obtain a quick response. In this global picture, the Arab Universities have to face a great challenge, which is not only economical but mainly cultural where social media become the tool for an innovative communication which encourages connection between students and firms in local and in global market. For this reason it's interesting to analyze the role of social media in local Universities with approach in which students are active participants in their own placement and they develop a model more collaborative and human that challenges dogmas of communication deeply held inside academic organizations to create a "new value".

The paper aims at providing an analysis of the phenomenon of social communication in Arab universities through the analysis of the percentage of presence and 
survival of these social networks and the use of this instrument. The purpose of this study is to investigate the different underlying needs and preferences that drive students towards job search and to understand if Arab Universities use the same instrument. This study can be useful for managers of universities and firms to understand that whether the presence of Universities on social media by students and firms is perceived as positive or not.

\section{Objectives and methodology}

The objective of this study is to identify the top Arab Universities with impact in the web world and analyzing if the support of innovative communication systems develops competitive advantage for placement in University of Arab world.

In general, the analysis followed the descriptive approach and a survey method. In particular, the study tries to answer the following research questions:

RQ1. Is there a correlation between innovative communication systems and placement processes in Universities of Arab World?

RQ2. And if it is positive, which is the weight of each tool in the use of the university career service?

RQ3. Do students positively evaluate the presence of these innovative communication systems in the page of University Career Centre?

To estimate the perception of the presence of these innovative communication systems in the page of University Career Centre, four items have been used: Career opportunities, Events, Mission, Storytelling.

- Career opportunities were available on the social media page and they explain Location, General conditions, Description, Application form.

- Events include news, new stories, deals, videos.

- Mission highlights corporate vision (for example: About us, Our company, Project ).

- Storytelling allow students to immerse into the Universities reality, to understand the lifestyle and values of the University, to get in touch with students and to understand their experience in the organization.
The Career Office provides a variety of services to help students meet their final goal: to pursue careers. The sets of offered services may vary for each University, but the most common we met during the analysis of their pages are the ones in the following picture

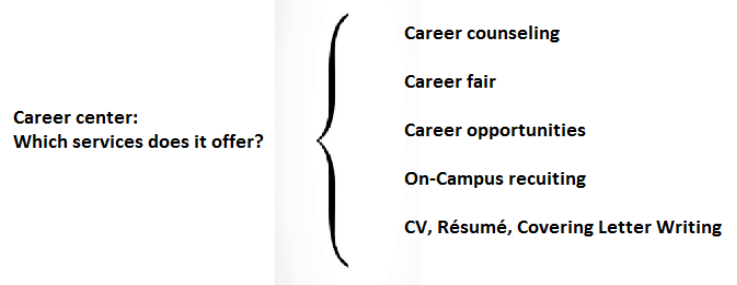

Figure 1 Career Centres' page

RQ4. Could innovative communication systems develop competitive advantage for placement in University of Arab world?

\section{Search sample surveys}

The research topic is very complex; therefore, the empirical analysis has been a key point to address it. It is subdivided into three parts.

In the first part there has been the identification of all Universities of Arab world that are on the web to analyze which are the social media that are significantly used by Career Centers (RQ1, RQ2). In this phase we have collected data using "Ranking of web universities" website (Webometrics website ${ }^{1}$ ) present in Arab World in 2017.

The Ranking Web is "the largest academic ranking of Higher Education Institutions. This ranking is performed by the Cybermetrics Lab each six months since 2004, with the purpose to provide people with information about the performance of universities from all over the world based on their web presence and impact"”.

The below figure summarizes the actual coverage of the ranking, in terms of number of institutions per country around the Arab world (for a total of 1.570 in 22 countries).

\footnotetext{
${ }^{1}$ Link to ranking: http://www.webometrics.info/en/world

${ }^{2}$ http://www.webometrics.info/en/world
} 


\begin{tabular}{|c|c|}
\hline \multicolumn{2}{|c|}{ Ranking of web universities ( Webometrics website) } \\
\hline Regions & Number of ranked universities \\
\hline ALGERIA & 103 \\
\hline BAHARANI & 15 \\
\hline COMOROS & $/$ \\
\hline DJIBOUTI & 1 \\
\hline EGYPT & 60 \\
\hline IRAN (Islamic republic of) & 584 \\
\hline IRAQ & 76 \\
\hline JORDAN & 35 \\
\hline KUWAIT & 12 \\
\hline LEBANON & 41 \\
\hline LIBYA & 14 \\
\hline MAURITANIA & 4 \\
\hline MOROCCO & 166 \\
\hline OMAN & 33 \\
\hline PALESTINIAN TERRITORIES & 18 \\
\hline OATAR & 7 \\
\hline SAUDI ARABIA & 54 \\
\hline SOMALIA & 22 \\
\hline SUDAN & 39 \\
\hline SYRIAN ARAB REPUBLIC & 24 \\
\hline TUNISIA & 187 \\
\hline UNITED ARAB EMIRATES & 51 \\
\hline YEMEN & 24 \\
\hline
\end{tabular}

Figure 2 Number of Universities per country around the Arab world

In the second part of the research we have restricted the field of investigation to analyze how Universities Career Centers (grouped for areas) use Facebook, Twitter, Instagram and LinkedIn (RQ3). We have focused on the leading institutions with the respect to four areas: teaching, research, employability and internationalization, using QS World University Ranking. It is based on six performance indicators ${ }^{1}$

- Academic reputation, whose weight is $40 \%$

- Employer reputation, whose weight is 10\%

- $\quad$ Student-to-faculty ratio, whose weight is $20 \%$

- Citations per faculty, whose weight is $20 \%$

- International faculty ratio, whose weight is 5\%

- International students ratio, whose weigh is $5 \%$

Thus, the sample was composed by 37 Universities of 13 countries, located in the Arab world (Figure n. 3):

\begin{tabular}{|c|c|}
\hline \multicolumn{2}{|c|}{ Ranking of world university (QS Top Universities website) } \\
\hline Regions & Number of ranked universities \\
\hline BAHARANI & 2 \\
\hline EGYPT & 5 \\
\hline IRAQ & 2 \\
\hline JORDAN & 2 \\
\hline KUWAIT & 1 \\
\hline LEBANON & 3 \\
\hline MOROCCO & 1 \\
\hline OMAN & 1 \\
\hline PALESTINIAN TERRITORIES & 1 \\
\hline QATAR & 1 \\
\hline SAUDI ARABIA & 7 \\
\hline UNITED ARAB EMIRATES & 6 \\
\hline IRAN & 5 \\
\hline
\end{tabular}

Figure 2 Sample of second phase of research

\footnotetext{
${ }^{1}$ More about methodology:

https://www.topuniversities.com/qs-world-universityrankings/methodology
}

The third phase of research was very laborious and it is focused to understand if innovative communication systems could develop competitive advantage for placement in University of Arab world (RQ4). Data collection were carried out by following three steps:

a) In the first step we have contained the list of Arab Universities to be analyzed later, using QS Graduate employability rank (QS Top Universities website ${ }^{2}$ ), that is an item that compare university performance in terms of graduate employability outcomes and prospect. It is based on five performance indicators:

- Employer reputation (30\%)

- Alumni outcomes (25\%)

- Partnerships with Employers per Faculty (25\%)

- Employer/Student Connections (10\%)

- Graduate employment rate (10\%)

The sample of Universities was, at last, of 16 Universities dislocated in 7 Countries (Figure n. 4)

\begin{tabular}{|l|l|}
\hline Ranking of QS Graduate employability \\
\hline Regions & Number of ranked universities \\
\hline EGYPT & 4 \\
\hline LEBANON & 2 \\
\hline IRAN & 2 \\
\hline JORDAN & 1 \\
\hline KUWAIT & 1 \\
\hline SAUDI ARABIA & 3 \\
\hline UNITED ARAB EMIRATES & 3 \\
\hline
\end{tabular}

Figure 3 Sample of Universities

b) In the second step we have contacted the students of each University, sending a first mail where the purpose of the research was explained. This phase lasted six months.

c) In the third step a questionnaire to evaluate the research hypothesis (RQ4) was sent. It was a html file which we inserted on Facebook page allowing all the individuals to respond easily and allowing us to re-elaborate the results in real time. The questionnaire was initially tested on a limited number of users, in order to understand at which point the questions were correct and the presentation form was accepted. The research was developed directly on the Internet. All questions provided a closed answers that we have catalogued as dichotomous dummies: " 1 " if the student positively evaluate, and " 0 " if they don't positively evaluate.

\footnotetext{
${ }^{2}$ Link to ranking:

https://www.topuniversities.com/university-

rankings/employability-rankings/2018
} 
Once a final database was created, sample surveys with questionnaires of this study were built. In particular, 400 students were contacted, but the sample at last was composed of 292 students, with a partial representation of the analyzed Universities. The sample is very small but it could be useful to define a potential trend. It's necessary to consider that, in a lot of Arab countries, there is war and people are very reserved. So this can be a good starting point for a future research.

\section{Data analysis and Results}

On the basis of hypothesis constructions (RQ1, RQ2) the research propose a regression model for statistical testing.

\begin{tabular}{|c|c|c|c|c|c|}
\hline Source & ss & df & MS & Number of obs $=$ & 1.570 \\
\hline & 860669295 & & 215167324 & $\begin{array}{l}\mathrm{LR} \operatorname{chi} 2(4)= \\
\text { Prob }>\operatorname{chi} 2=\end{array}$ & $\begin{array}{l}65.84 \\
0.0000\end{array}$ \\
\hline Residual & 6.04593863 & 185 & 0.32680749 & Pseudo $\mathrm{R} 2=$ & 0.5874 \\
\hline Total & 14.6526316 & 1570 & 0.77527151 & $\begin{array}{l}\text { Adj R-squared = } \\
\text { Root MSE = }\end{array}$ & $\begin{array}{r}0.5785 \\
18078\end{array}$ \\
\hline
\end{tabular}

\begin{tabular}{|c|c|c|c|c|c|}
\hline Socialmediause & Coef. & Std. Err & z & $P>|z|$ & [ $95 \% \%$ Conf. Interval] \\
\hline Facebook & 3.844237 & .9224435 & 4.17 & 0.000 & $2.036281 \quad 5.65219$ \\
\hline Twitter & 2.397552 & 1.56748 & 1.53 & 0.026 & $6746516 \quad 5.469756$ \\
\hline Linkedin & 1.904114 & 1.064478 & 1.79 & 0.074 & $.1822231 \quad 3.990452$ \\
\hline Instagram & -1.131461 & -1.678627 & -0.67 & -0.500 & $-4.42151 \quad 2.158588$ \\
\hline cons & -1.852218 & .7189666 & -2.58 & -0.010 & $-3.261367 \quad .4306094$ \\
\hline
\end{tabular}

Figure 4 Regression results

This regression shows that all the social media included in the analysis are significantly used by Career Centers (their p-values are lower than 0.05), except from Instagram, because the p-value proves it is not relevant. This result depends on the fact that there are few data on Instagram, due to the different usage it is connected to. Moreover, considering the coefficients, Facebook is the most popular social media such as Twitter. All the coefficients are positive, thus, the relationship among variables is positive and when "social media" increases, all the regressors increase too.

In the below graphs it is showed how Career Centers (grouped for areas) use Facebook, Twitter, Instagram and LinkedIn.

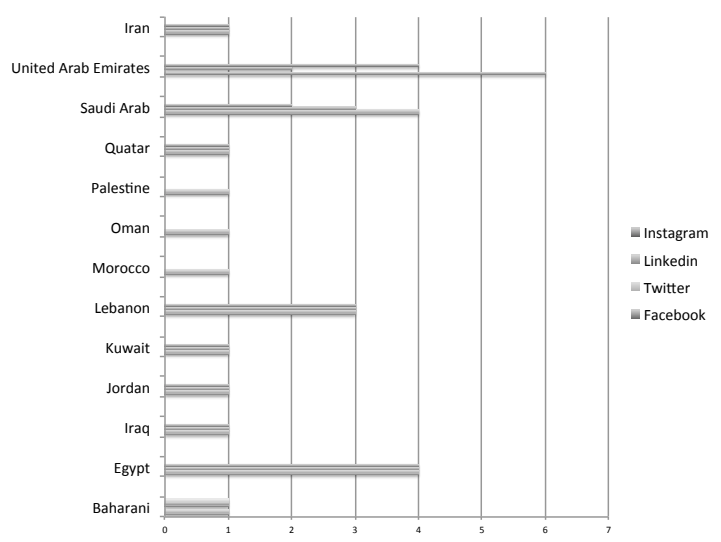

Figure 5 Use of different social media in Career Centres of Arab Universities

For each geographical region (on the y-axis), the first bar measures the number of centers which have a profile on Facebook, the second one how many use it to post job opportunities, to advertise events or to emphasize the missions or the storytelling of the university. Of course, these numbers have to be read considering the structure of our sample size, in which most of the universities are located in Egypt, United Arab Emirates, Saudi Arab and Lebanon. Thus, by looking at it, we can assert that almost all of the offices use this Social Media, except from Iran, Quatar, Palestine, Oman, Morocco, Kuwait, Jordan, Iraq and Baharani where the number of users is less high compared to the others. The most performed activity is advertising events and promoting university's missions and storytelling. Moreover, almost half of Institutions, that have a profile, use it to post job offers.

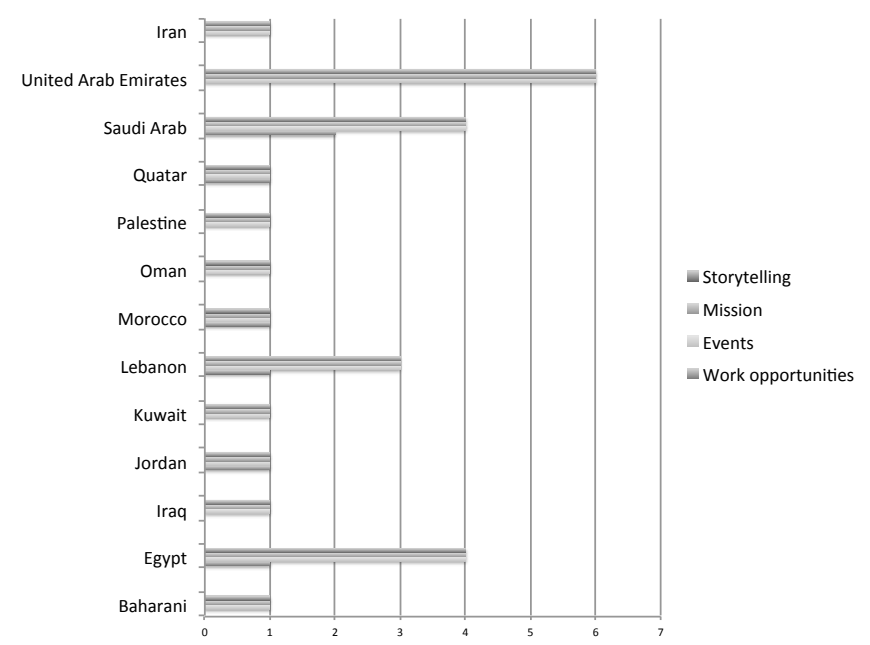

Figure 6 Facebook use in the career centres

This bellow graph (Figure n. 8) is interpreted as the previous one, but it deals with the use of Twitter. The 
number of institutions who are registered remains very low, except from Saudi Arab, Egypt and Lebanon where there is a middle presence. As a social media thought to share ideas, picture and comments, it is not properly used for the purposes we considered but a large amount of career offices look at it as an interesting platform to promote events. Just a small number views it as a platform to post job offers.

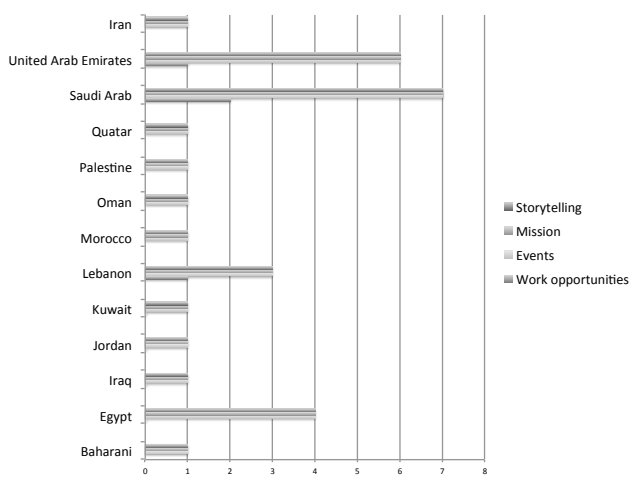

Figure 7. Twitter use in the Career Centres

The graph referred to LinkedIn proves that this social media is used for "more professional" activities. It is due to the fact that it arises as a professional network. Egypt, Saudi Arab and Lebanon consider LinkedIn a way to publicize job and a platform where advertising events.

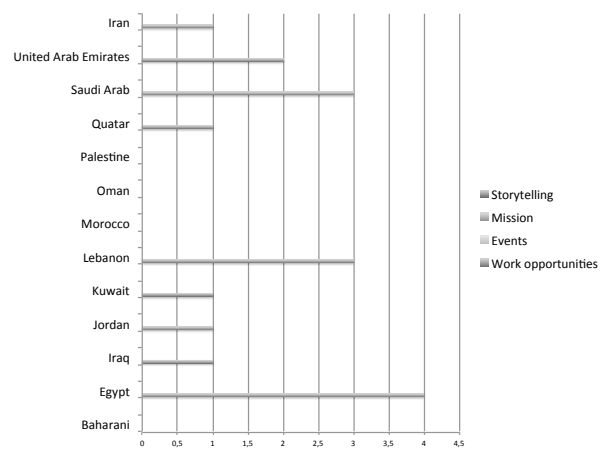

Figure 8 LinkedIn use in the Career Centres

Instagram is the last social media we analyzed and, as a site connected to photos posting, it is not diffuse among career centers. We found less information about it, because not all the career services enrolled in it. However, it is hardly ever used for job posting and often for advertising events and evaluating the storytelling.

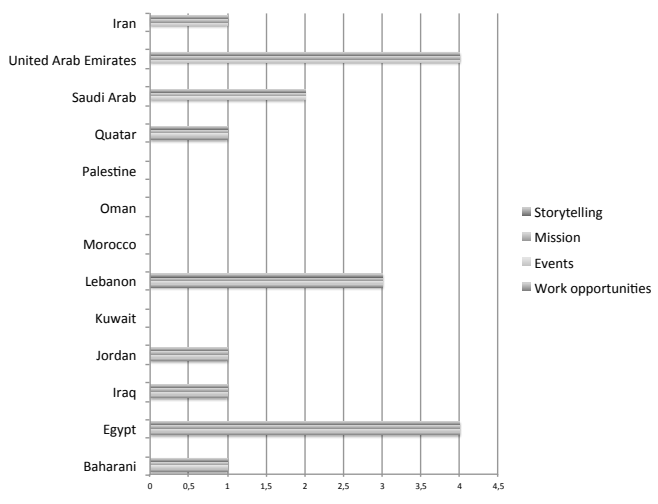

Figure 9. Instagram use in the Career Centre

RQ3. Do students positively evaluate the presence of these innovative communication systems in the page of University Career Centre?

In order to examine what perception of the Universities Carrer Centres the students have had, they have been asked to evaluate the contents of the sites of the surveyed Universities. The research, through the use of the logistic regression method, has analyzed whether there is, in the opinion of the students, a relationship between use of social media (Facebook, LinkedIn, Twitter, Instagram) and Placement in terms of Career opportunities, Events, Mission, Storytelling.

In the Logit model (Table n.1) all the observed coefficients show a significance level very close to zero. This regression shows that Facebook is related to the different ways in which it is used by the Career Centres: to advertise event, to promote work opportunities and, finally, to underline the missions and the storytelling of the university.

Table 1Regression model on Facebook use

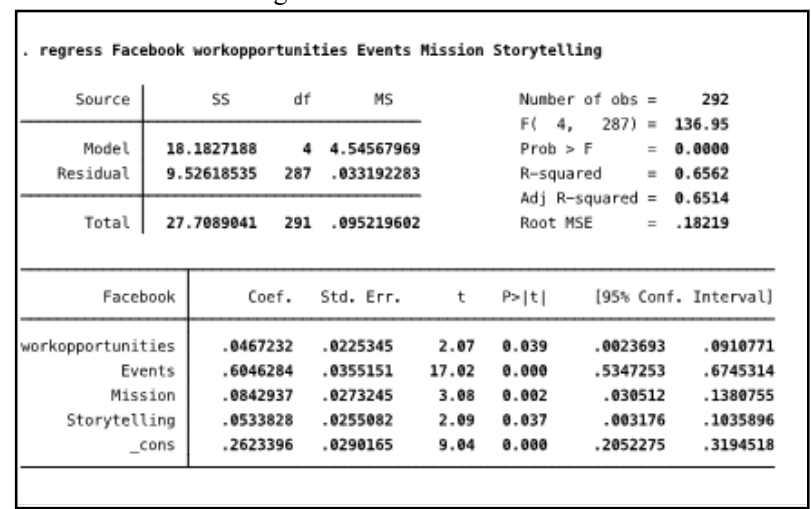


All these variables show statistical significance as the pvalues are lower than 0.05 and, thus, are relevant, in the sense that the students have found information on all the "activities". By looking at the coefficients, we can deduce that Facebook is predominantly a means to advertise events (such as career fair, on-campus recruiting and presentations), to share mission values, and only partially used to publicize jobs. The tendency to promote jobs on Facebook is still not a usual procedure in Arab world.

Table 2 Regression on Twitter use

\begin{tabular}{|c|c|c|c|c|c|c|}
\hline \multicolumn{4}{|c|}{ regress Twitter $\mathrm{AA} A \mathrm{AB}$ AC $\mathrm{AD}$} & \multirow{5}{*}{\multicolumn{2}{|c|}{$\begin{array}{l}\text { Number of obs } \\
F(4, \quad 252) \\
\text { Prob }>F \\
\text { R-squared } \\
\text { Adj R-squared } \\
\text { Root MSE }\end{array}$}} & \multirow{3}{*}{$\begin{array}{r}=257 \\
=\quad 21.06 \\
=0.0009\end{array}$} \\
\hline Source & ss & \multicolumn{2}{|c|}{ MS } & & & \\
\hline Model & 7.13877322 & 4 & 46933 & & & \\
\hline Residual & 21.3592813 & 252.08 & 59053 & & & $=0.2505$ \\
\hline Total & 28.4980545 & 256.11 & 20525 & & & $\begin{array}{l}=0.2386 \\
=\quad .29113\end{array}$ \\
\hline Twitter & coef. & Std. Err. & t & $P>|t|$ & {$[95 \%$ conf. } & Interval] \\
\hline AA & . .0647863 & . 0451274 & 1.44 & 0.152 & -.0240887 & .1536612 \\
\hline AB & .2410526 & .0434873 & 5.54 & 0.000 & .1554077 & .3266974 \\
\hline AC & .0127153 & .0454092 & 0.28 & 0.780 & -.0766969 & .1021275 \\
\hline AD & . 1740506 & .9399129 & 4.36 & 0.000 & .0954453 & .2526559 \\
\hline _cons & .6511111 & .0311624 & 20.89 & 0.000 & .5897391 & .712483 \\
\hline
\end{tabular}

The analysis of Twitter shows that it is not used to promote job opportunities or to underline the mission of the university but to advertise events and to talk about its storytelling. This site is most widely known for its use by media outlets and celebrities, but can also be a great way for people to interact with colleagues or people of similar professional interests from all over the world.

Table 3 Regression on LinkedIn use

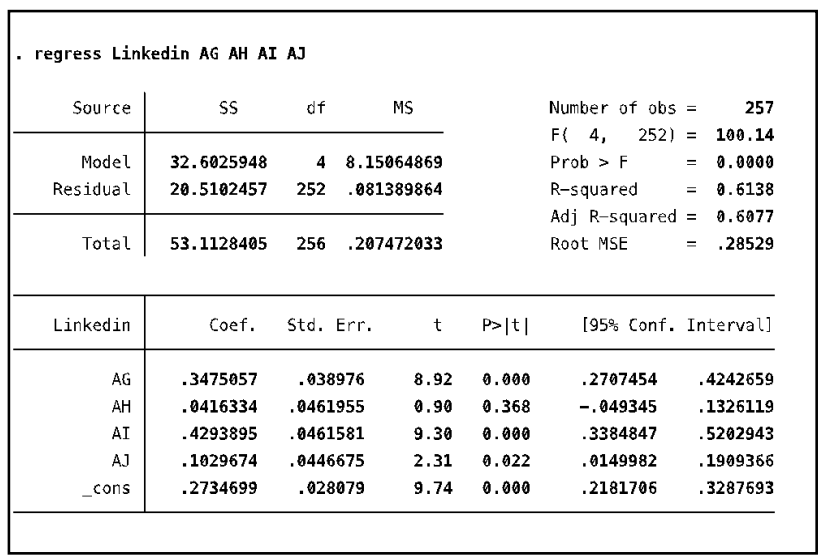

The analysis focused on the different activities of the career offices on LinkedIn proves that the platform is not used to advertise events ( $p$-value $>0.05$, variable not statistical significant) but, as a professional social network, both to promote job opportunities and underline the missions. The coefficient linked to work opportunities highlights that a 1 percentage point increase in the use of LinkedIn (of course, by the Career Centre), is connected to a 0,34 percentage points increase in the spot given to job opportunities. This result does not surprise us, given that the aim of this website, since his birth, has been to link professionals in order to increase their productivity and success. In this perspective, it is a key element for the procedure of job placement fostered by the career offices.

Table 4 Regression on Instagram use

\begin{tabular}{|c|c|c|c|c|c|c|c|}
\hline \multicolumn{8}{|c|}{ regress Instagram AM AN A0 AP } \\
\hline Source & ss & $d f$ & \multicolumn{2}{|c|}{ MS } & & \multirow{2}{*}{$\begin{array}{l}\text { Number of obs } \\
F(4,286) \\
\text { Prob }>F\end{array}$} & \multirow{2}{*}{$\begin{array}{rr}= & 291 \\
= & 41.43 \\
& =0.0000\end{array}$} \\
\hline Model & 24.9178273 & 4 & \multicolumn{2}{|c|}{6.22945682} & & & \\
\hline Residual & 42.9996985 & 286 & .150 & 48596 & & \multirow{2}{*}{$\begin{array}{l}\text { R-squared } \\
\text { Adj R-squared } \\
\text { Root MSE }\end{array}$} & $=0.3669$ \\
\hline Total & 67.9175258 & 290 & \multicolumn{2}{|c|}{.234198365} & & & $=.38775$ \\
\hline Instagram & coef. & std. & Err. & $\mathrm{t}$ & $P>|t|$ & [95: conf. & Interval] \\
\hline AlM & .0722942 & .8990 & 631 & 0.73 & 0.466 & -.122691 & .2672793 \\
\hline AN & .2823336 & .0623 & 257 & 4.53 & 0.000 & .1596583 & .4050088 \\
\hline A0 & .0911564 & .8679 & 843 & 1.34 & 0.181 & -.0426567 & .2249696 \\
\hline AP & .4235645 & .0560 & 916 & 7.55 & 0.000 & .3131598 & .5339691 \\
\hline _cons & .3907652 & .0293 & 952 & 13.33 & 0.000 & .333084 & .4484464 \\
\hline
\end{tabular}

The regression on Instagram's usage by the career office states that it is an important mean to advertise events and talk about the storytelling. Work opportunities and mission has not shown to be relevant, in this case. Actually, it was predictable because this social involves pictures' posting and these pictures might be events' posters or emblematic images related to the story of the university and of students. There is a substantial homogeneity in the answers regarding the geographical distribution of students.

\section{Conclusions}

Universities occupy a central role in the ways we live our lives.

Building modern Universities, able to exploit new forms of communication which strongly facilitate contact between people of countries and cultures different, it can transform in social equality, in environmental sustainability, in capacity to maximize human potential and, at macro levels, it turns attention to organizational identity, culture, reputation, legitimacy and character.

The increasing popularity of the Internet has resulted in a profound change in the patterns of interaction and communication between individuals and organizations (Universities) also in Arab countries. But it's necessary to highlight that although in the last years Internet penetration and social media penetration has greatly increased to make knowledge sharing a voluntary action, it has to create the right conditions, instilling in individual workers the desire to share knowledge. The real problem is that many people prefer to share knowledge only if they see a benefit. 
For this reason we have analyzed the perception of the use of Facebook in Universities and in particular in the recruitment process. Social recruitment is, today, one of the major challenges that are required to HRM if they wish to remain competitive in the new environment.

There is a strict relationship between competitive advantage and recruitment strategy. Our study shows that in the universities of analyzed countries the perception of the utility of UCS on Facebook is positive. For this reason, the assumptions of traditional job placement of an individual can trap Universities into ways of thinking and action that are not in their best interest.

Our study shows that in the universities of seven countries the students' perception of the utility of UCS on Facebook is positive. For this reason, the assumptions of traditional job placement of an individual can trap Universities into ways of thinking and action that are not in their best interest. In such circumstances, it is important to develop alternative forms that reflect upon the complexity of the market. Such changes oblige governance to define new techniques and strategies that concern the process of recruitment, maintaining a set of own meanings of the individual's culture. In social interaction individual brings a typical cultural background of the reality that is lived daily by assigning different meanings to the interaction. In complex contexts, such as in the Arab world, interaction takes place by using information proper to the culture in which it is inserted (Mantovani, Riva, 2001). The choice of social media as tool for communication could contrast with the values, traditions and uses of local culture of a country changing, for example, the relationships between two users: instead of respecting the status relative to each other (high power distance), it treats everyone as a "friend" (low power distance). So, in the last years, numerous researchers have applied the analysis of cultural dimensions to the studies of Internet-related communication (Rosen et. al, 2010; Marcus and Gould, 2000; Lee, 2000; Zahir, Dobingand and Hunter, 2002; Brown et al, 2006; Srite and Karahanna, 2006), but few studies contain specific and explicit reference to each cultural dimension and to social media. In a previous study (Gravili, 2015) we have demonstrated that there is a relationship between Hofstede's cultural dimensions and social media penetration. In particular Individualism and Indulgence are positively correlated to social communication' use, while Masculinity is negatively related to the use of social media communication.

Table 5 Hofstede's cultural dimension of the sample.

\begin{tabular}{|l|l|l|l|l|l|l|l|l|l|l|l|}
\hline \multicolumn{4}{|l|}{ Lebanon } & \multicolumn{3}{l|}{ Jordan } & \multicolumn{2}{l|}{$\begin{array}{l}\text { United } \\
\text { Emirates }\end{array}$} \\
\hline I & M & IN & I & M & IN & I & M & IN & I & M & IN \\
N & A & D & N & A & D & N & A & D & N & A & D \\
D & S & U & D & S & U & D & S & U & D & S & U \\
\hline 40 & 65 & 25 & 30 & 45 & 43 & 25 & 50 & - & 25 & 40 & - \\
\hline
\end{tabular}

Table 6 Hofstede's cultural dimension of the sample.

\begin{tabular}{|l|l|l|l|l|l|l|l|l|}
\hline \multicolumn{4}{|l|}{ Saudi Arabia } & \multicolumn{3}{l|}{ Iran } & \multicolumn{2}{l|}{ Egypt } \\
\hline IN & MA & IND & IN & MA & IND & IN & MA & IND \\
D & S & U & D & S & U & D & S & U \\
\hline 25 & 60 & 52 & 41 & 43 & 40 & 25 & 45 & 4 \\
\hline
\end{tabular}

So, considering Table n. 5, in which are defined Hofstede's dimensions, it's evident that although not sharing a physical space share a mental (or digital) one, students like to give information on their recruitment processes, to cooperate, to interact, to share and to act through a continuous sharing of information. All participants would like found answers to their specific informational needs in a less conventional way than in the real world, using simple language and within limited time. In all four countries social media penetration $(\mathrm{smp})$ varies in a range between $48 \%$ and $51 \%$ (Figure n. 5), so there is a positive perception of $\mathrm{Fb}^{\prime}$ use and in fact, in these countries, social media as well represent an innovative channel to develop collaborative dynamics within organizations.

Competitive organizations must now develop the ability to attract individuals who can stimulate innovation behavior or who know how to acquire the techniques and principles of creativity. Consequently, the knowledge-oriented organizations should always select subjects that are quickly adapted to the change.

\section{References}

[1] Galanaki, E. (2002). The decision to recruit online: A descriptive study. Career development international, 7(4), 243251.

[2] Veger, M. (2006, January). How does Internet recruitment have effect on recruitment performance?. In Fourth Twente Student Conference on IT (Vol. 30).

[3] Verhoeven, H., \& Williams, S. (2008). Advantages and disadvantages of Internet recruitment: A UK study into employers' perceptions. International review of business research papers, 4(1), 364-373.

[4] Schramm, J. (2007). Internet connections, HRMagazine, vol.52, no. 9.

[5] Furness, V.(2008), “The new frontier”, Personnel Today, January 2008.

[6] Verhoeven, H., \& Williams, S. (2008). Op. cit.

[7] Gallagher, N., \& O'Leary, D. (2007). Recruitment 2020. How recruitment in changing and why it matters, Demos

[8] Tariq, W., Mehboob, M., Asf, M., \& Khan, Y. (2012). The Impact of social media and social networks on education and students of Pakistan, IJCSI International Journal of Computer Science Issues, Vol. 9, Issue 4, No 3, July 2012

[9] Fatima, S., Manzoor, U., Zafar, B., \& Balubaid, M. A. (2015). Analyzing the Impact of Social Media on Users. International Journal of Computer Science Issues (IJCSI), 12(3), 141 
[10] Gravili G., (2015), Social communication in management: implications in recruitment processes of Latin American countries, in proceeding of ECMLG 2015.

[11] Gravili, G., \& Fait, M. (2016). Social Recruitment in HRM: A Theoretical Approach and Empirical Analysis. Emerald Group Publishing Limited.

[12] Marcus A. and Gould E.W (2000), "Crosscurrents: Cultural Dimensions and Global Web User Interface Design, Interactions, 7:4, July/August 2000, 32-46.

[13] Norman R. (2000), Service Management: Strategy and Leadership in Service Business, 3ed., John Edit.

[14] Rogers E.M., (1995), Diffusion of innovations (4 Ed.) New York:Free Press.

[15] Rosen et. al. (2010), An Empirical Examination of the Educational Impact of Text Message-Induced Task Switching in the Classroom: Educational Implications and Strategies to Enhance Learning, in Psicología Educativa Vol. 17, n. ${ }^{\circ} 2$.

[14] Srite, M. \& Karahanna, E., 2006, 'The role of espoused national cultural values in technology acceptance', MIS Quarterly 30(3), 679-704.

[16] Williams, S., and H. Verhoeven (2008), “'We-find-you' or 'You-find-us' - Internet Recruitment and

Selection in the United Kingdom," International Review of Business Research Papers, Vol. 4 No. 1, 2008 pp. 374-384.

[17] Zahir, S., B. Dobing, and M.G. Hunter, (2002) "CrossCultural Dimensions of Internet Portals," Internet Research, Vol. 12, No. 3.

Ginevra Gravili, was born in Lecce on 07 October 1969. She graduated in Economic Studies in 1992, and she achieved PHD in Management and Organization in 1996. Since 2002, she is professor of Organization Theory at University of Salento, Department of Economics and Management, Lecce, Italy. She has written numerous books and articles on social media, social recruitment, knowledge sharing, HRM, public administrations, Health organizations. 